\title{
فلسفة المرآة
}

$$
\text { د. عمر مصطفى لطف وتعليق }
$$

فلسفة المرآة / محمود رجب ـ ـ- القاهرة :

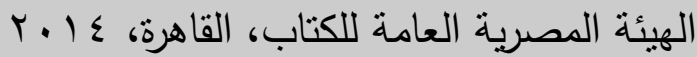
rاسص ؛ $9 \vee \wedge-9 \vee \vee-91 \cdot-. \vee 1-0$ تدمك 
من قبل، منل "الجسم والإدرالك الحسي والضحك إلخ.." وأصبحت هذه الموضوعات عناوين رئيسية لمؤلفات وضعها نفر من كبار الفلاسفة. وتهدف الفلسفة من اقترابها من الحياة اليومية للإنسان، فهم الوجود بعامة والوجود الإنساني

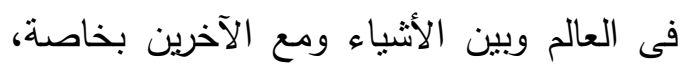
وعلى هذا الأساس العام يغدو تساؤلنا الفلسفي عن المرآة وانعكاسها أمرًا ممكنًا ولا يخلو من لن

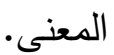
وفى نهاية مقدمة كتابه، يوضتح الكاتب الهدف من دراسته، بأنه مادامت المرآة جديرة بالدراسة الفلسفية، فكيف يمكن لهذه الدراسة أن تقوم؟ وما الذي بمكن أن تقودنا إلبه؟ فإذا كان فهم الوجود عامة ووجود الإنسان في العالم خاصة هو ما

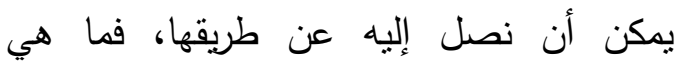

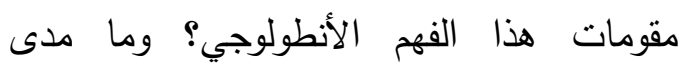

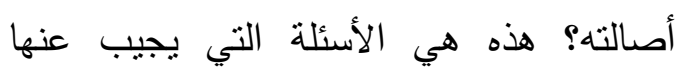

$$
\text { الكتاب عبر أبوابه وفصوله. }
$$

في بداية الفصل الأول من الباب الأول،

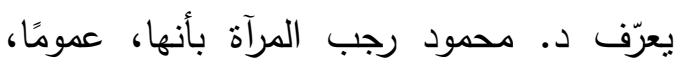
عبارة عن سطح يعكس كل ما يقوم أمامه. فأي شىء يمتلاك خاصية السطح العاكس، فهو مرآة. وكلما كان أنقى وأصفى، كان مرآة أفضل. وهذا الذي يقوم أمام المرآة يُعرف باسم الأصل. وأما الذي تعكسه فهو يُعرف بالصورة أو الانعكاس.

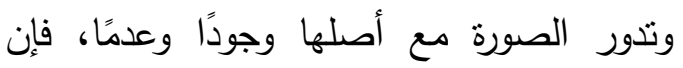

يتكون من مقدمة بعنوان "الفلسفة والمرآة"، ثم يتلوها بابان، الأول؛ وهو بعنوان "ظاهرة المرآة" - يندرج فيه فصلان أولهما بعنوان

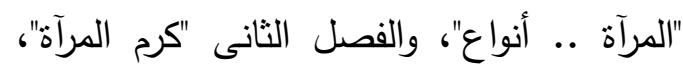
وينقسم الباب الثاني - وهو بعنوان "تجربة المرآة" - إلى بابين أيضًا، وأولهما عنوانه "أنا - بلهوان آخر"، والفصل الثاني بعنوان "الرواى - المروى بابن عنه"، ثم ينهي الكاتب كتابه بعرض مصادر دراسته ومراجعها. بطرح الكاتب - فى بداية مقدمة كتابه -

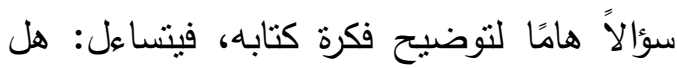
يمكن على الإطلاق قيام دراسة فلسفية حول

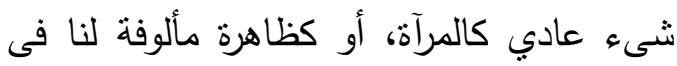
حياتتا اليومية منل ظاهرة المرآة؟ خاصة وأن الفكرة الثائعة عن الفلسفة، أنها دراسة عقلية علية جادة لا نتتاول سوى موضوعات وحقائق بالغة التجرد. ولكن الفلسفة علميًا اهتمت منذ بداياتها الأولى بالأشياء العادية والمعتادة في الحياة، لم

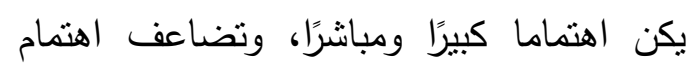
الفلسفة بالحياة اليومية إلا فى القرن العشرين،

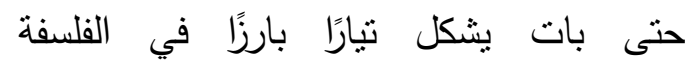

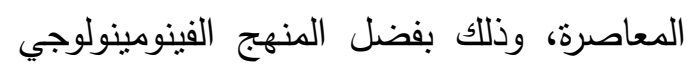
(الظاهرياتي) من ناحية، وتحليلات الفلاسفة الوجوديين الذين اعتمدوا بدرجات متفاوتة على نلى هذا المنهج من ناحية أخرى، وفلاسفة التحليل من ناحية ثالثة. ولهذا نرى الفلسفة المعاصرة تتناول أشياء وظواهر كانت تُعد عديمة القيمة ناهة 
يظهر جيشًا، وبحيث يمكننا أيضًا أن نُظهر في

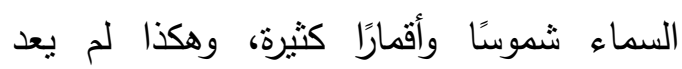
مقصورًا على تجارب تُجرى في داخل معامل

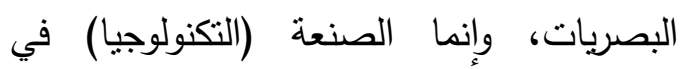
مقدرها أيضًا أن تتخل فتستخدم التجمعات الهائلة من مرايا البخار والسحاب فى الطبيعة ذاتها.

كان العلم حينذاك ممتزجًا، ليس فقط بالفلسفة، و وإنما أيضًا بالخرافة والأساطير والسحر والتتجيم. وكانت كتب العلم أو الفلسفة والنها باطير الطبيعية تحمل عناوين دالة على هذا المزج وليج العجيب (منل كتاب "الفلسفة الغيبية" لأجريبا)، كما كانت مليئة برسوم لمرايا السحاب والبخار التى تعكس جيوشًا وحيوانات وملائكة وقديسين .. إلى آخر هذه الصور التي كانت توصف أحيانًا بأنها معجزات تظهر في السماء. وتللك هي الأصول التاريخية البعيدة لما لا يزال يحدث حتى زماننا المعاصر من ظواهر مماثلة.

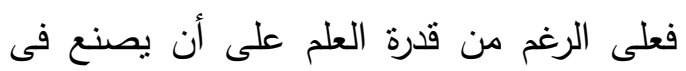

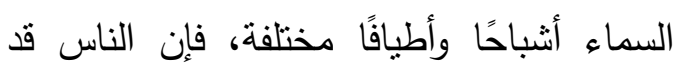
ترى في تجمعات السحاب ما تود أن تراه،

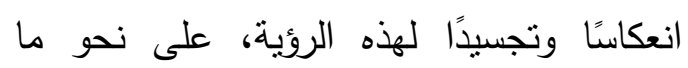

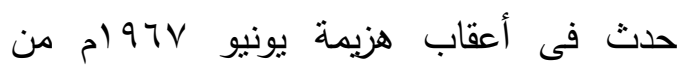
ظهور "السيدة العذراء" في سماء حي الزيتون بالعاصمة القاهرة. ويذكر الكاتب أن القمر والمطر والسحاب والهواء، تؤلف كلها إذن مرايا سماوية، وكأنما
وُجدت كان الأصل موجودًا، وإن انعدمت أو غابت كان الأصل منعدمًا أو غائًًا. وهذا يعني أن المرآة ليست فقط الصورة، وإنما هي تقدم للأصل، أو لحاملها، أو لمن ينظر إليها، صورة

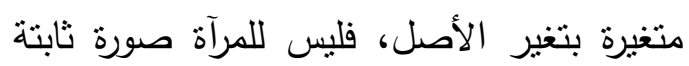

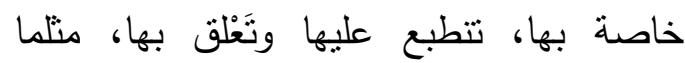
تتطبع صورة الخاتم على قطعة الثمع ونَعْق بها ويتحدث الفصل الأول عن أنواع المرآة، وهما نوعان: المرايا الطبيعية والمرايا المجازية. ويشمل النوع الأول - المرايا الطبيعية - عدة ولئ

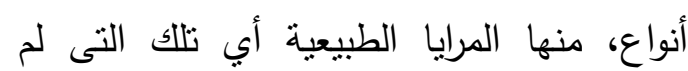
تتذخل فيها يد الإنسان بالصناعة أو التطوبر

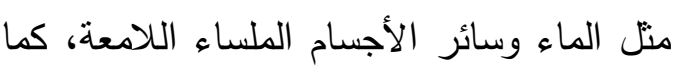
تشمل ما يتتاوله الإنسان من أثنياء الطبيعة الجناء بالصقل والصنع، حتى يصبح سطحًا عاكسًا، ويكون بالتالي مرآة صناعية.

وقد توقف المشتغلون بالفلسفة الطبيعية

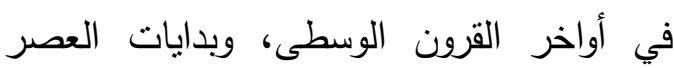
الحديث أمام مرايا السحاب والبخار وما ولهاب يصاحبها من تشكيلات مثيرة للاهشة، وطرحوا على أنفسهم السؤال الهام التالي: هل هذئه هذابه ظواهر هن الطبيعة والخيال أم هي ظواهر صناعية مصطنعة؟ فأشار روجر بيكون إلى أنه في استطاعتتا صنع أجهزة ومرايا من شأنها أن تجعل ما هو واحد يبدو متعددًا، والرجل الواحد 
المباه أو تمحوه سرعة الرياح، ومن هذه الحاجة اخترع الإنسان المرآة وقام بصناعتها، وكان ذلك الك الك فى مصر القديمة، حوالى . . .. ق. ق. م، وهى الإنى مرتبطة عنده - بجانب التزين - بمعتقداته وإبداعاته العلمية والفنية الأخرى، فأمله في لنده البقاء والخلود ، ورغبته فى أن تكون صورته

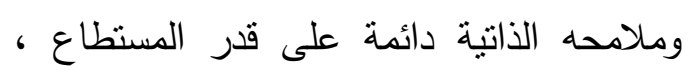
أدى به إلى أن يحول ملامحه إلى تمثال آدمي جاف مع جسده.

ولم تأخذ معالم علم المرايا في التحدد والوضوح إلا فى العصر السكندري، ثم فى ثئم العالم الإسلامي، وانضوى تحت لواء علم أوسع هو "علم البصريات" (الأوبطيقا Optique) أو الإسيات ما كان يسميه الإسلاميون "علم المناظر". وكانت توجد في أحاديث المشتخلين بهذا العلم، إثارات إلى الانعكاس يتجلى على سطوح

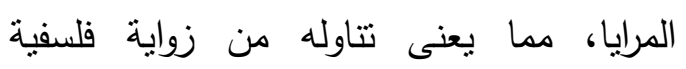

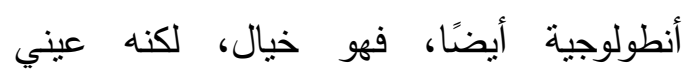
ومتعين، أى أن له وجودًا منظورًا وتجسمًا على أنى نحو من الأنحاء. كذلك نجد فى أقوالهم إثارات إلى خصائص المرآة، أو على الأدق أفعالها الغريبة ، مثل قلب الصورة أو عكسها، وتياسر

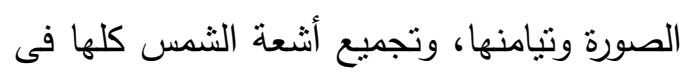
نقطة واحدة لإحراق ما يُراد إحراقه .. وغير ذلك

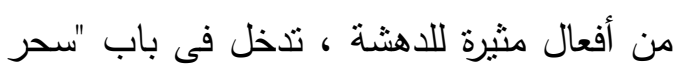

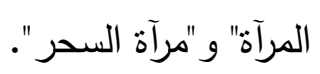

هي مشهخ أو مسرح سماوي متعدد الجوانب، فيه

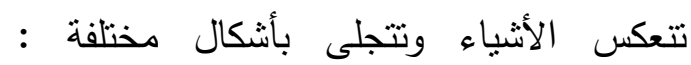
مصغّرة، ومكبّرة، ومتعددة إلى ماء لاهي لا نهاية. ومثلما تتعكس فى هذه المرايا - السماوية قوس ومنئرة قزح أو الثموس والأقمار المتعددة، وهي بلا لتهن حقيقة واقعية أو قوام مادي، تتعكس فيها أيضًا انبعاثات الروح وفيوضاتها، فتتذذ أشكالاً مرئية مجسمة.

هذا الالتقاء بين الروح والروية الذي

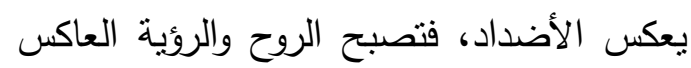
للأضداد، فنصبح الروح مرئية والمرئي روحانيا، نجد بداياته الباكرة في المذهب الأورفي، وفي لاني لردي الأفلاطونية المحدثة. فالأمر لم يعد مجرد فكر لـانه ينعكس، أو يتركز أو يتكثف في الهوائين وإنما عقول نرتكب الخطأ والخطيئة في السماء،

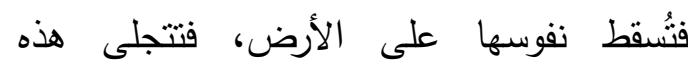
النفوس وتظهر بإضفائها الصورة على الأجسام.

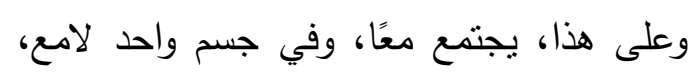

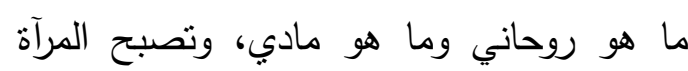
هي نقطة الالتقاء والتقاطع بين هذين الضدين المتعامدين.

أما المرايا الصناعية، فقيل إن الماء كان أول مرآة طبيعية في الوجود، ولهذا فعندما رأى الإنسان انعكاس وجهه مهنزًا مع رقرقة مياه النهر أو البحيرة، أحسّ بالحاجة إلى أن يكون النّان

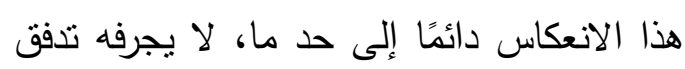


العدد الرابع والخمسـون - 7 •

$$
\text { ع- ع- مرآة الإنسان. }
$$

وهذا التصنيف غير قاطع في حدوده

الفارقة. فقضلا عن كونه غير جامع للمرايا

المجازية كلها، ولا مانع للمرايا الحقيقية من

الدخول فيه أو التقاطع معه، فإن ثمة تداخلاً لا لان

محيص عنه بين هذه المجموعات الأربع، كأن

يكون ما نعدّه في نص أو سياق مرآة إلهية، هو لآنه، نفسه فى نص آخر، وفي سياق مختلف، مرآة

$$
\text { كونية أو إنسانية أو سحرية. }
$$

وعن مرآة الله يتضح أن ثمة ارتباطًا وثثقًا

ودائمًا بين الآلهة والمرايا : الإله أمام المرآة، الله

- المرآة، الألوهية التى تتجلى فى مرآة صلبة جامدة (زجاج، ذهب، إلكتروم)، أو فى مرآة على هيئة بشر حي (موسى، الإمام المعصوم)،

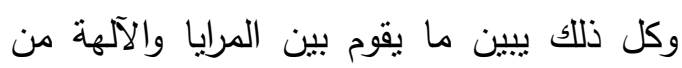

$$
\text { علاقات متعددة. }
$$

أما مرآة الإنسان فإن الجانب الأخلاقي

والتعليمي في وظيفة المرآة الانعكاسية هو لإن الانية

الجانب الغالب على مجاز الإنسان - المرآة،

وإن كانت الوظيفة المعرفية الابستمولوجية (والتى تؤدى إلى معرفة الذات) غير مستبعدة

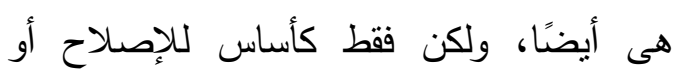
التهذيب الأخلاقي. فالاختلاف الكيفي الذي لإنيان بينتعره الإنسان بينه وبين الإنسان - المرآة
أما المرايا المجازية، فكان عنوان لعدد من الكتب والدوريات المنتوعة، وبمختلف اللغات، وهى امتداد لتراث طويل من العصور الوسطى

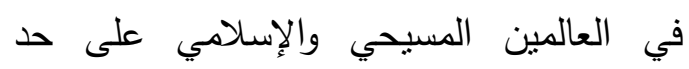
سواء، فقد كان لفظ "المرآة" بالعربية واللاتينية يتردد في عناوين المؤلفات على (Speculum) سبيل الرمز والمجاز في الأعم الأغلب. ويذكر البعض أن هناك أربعة أنماط من المرايا المجازية في عناوين هذه الكتب، دون أن الن الناطي نضطر إلى الاخول في تفاصيل ما تتضمنه من مواد:

1- مرآة تعكس الأشياء كما هي موجودة

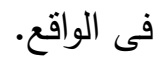

ץ- مرآة تبين الطربقة التي ينبغي، أو لا ينبغي، أن تكون عليها الأشياء. r- مرآة تبين الطريقة التي سوف تكون عليها الأشياء في المستقبل. ع- مرآة تبين ما هو موجود فقط في مرآة

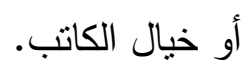

بينما بصنف الدكتور محمود رجب المرايا

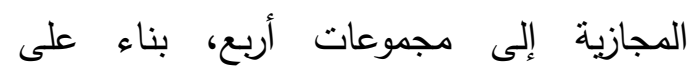

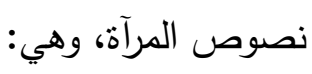

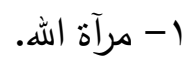

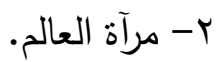


واستمر هذا أيضًا في العالم الحديث، منلما نقرأ في مسرحية "ماكبث" لثكسبير.

ولكن نظرًا لارتباط التكهن عن طريق

استعمال المرآة بنوع من السحر، يسمى السحر

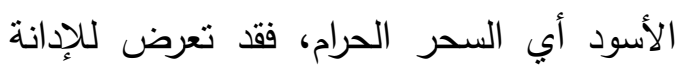

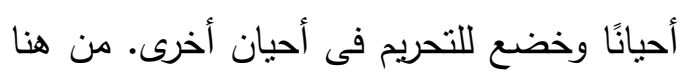

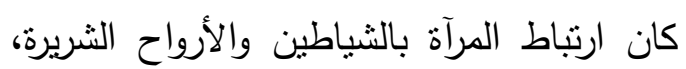

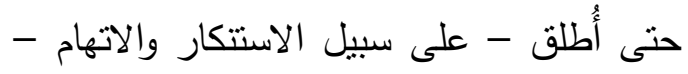
اسم المرآويين أو أصحاب المرايا على هؤلاء السحرة الذين كانوا يمارسون هذا النوع الثرير الثراب الثراء

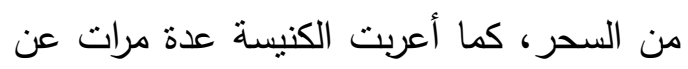
عدم ارتياحها إزاء ذللك الاعتقاد القائل بقدرة

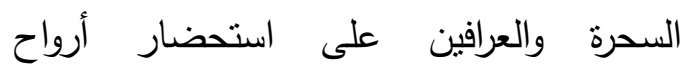

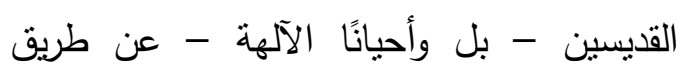
مراياهم، فنظهر واضحة جلية أمام الناظرين،

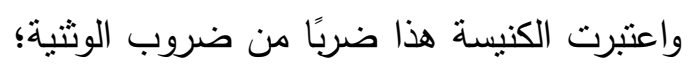

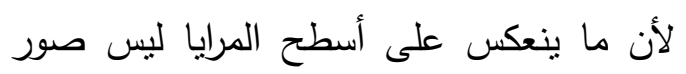

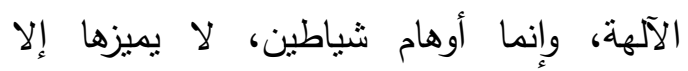
أصحاب النظرة البريئة الصافية كالأطفال لألهال والعذارى وأنقياء القلب. أما من هم غير أولئك التئي فإنهم لا يميزون الصورة الزائفة من الصورة

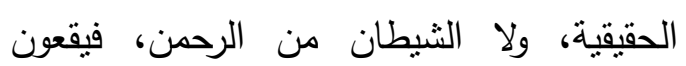
بالتالي في الخطأ والخطيئة.

وفي المصادر العربية، نجد أنواعًا متعددة

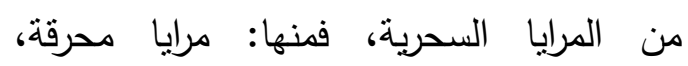
تستقطب أثنعة الثمس وتسقطها على سفن
الذي يجسد أمامه "مثالاً"، قد يؤدي به إلى

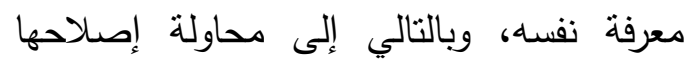

وتهذيبها.

وعن مرآة السحر، فهناك مخزون هائل

في تراث الإنسانية من المرايا ذوات القدرات

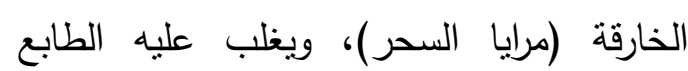
الأسطوري أو الخرافي، ولكن لابد من الإثشارة إلى أن العلم لم يكن منفصلاً عن السحر لألخ من الإنارة

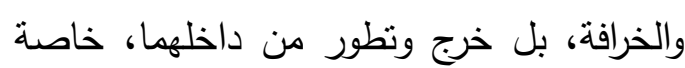

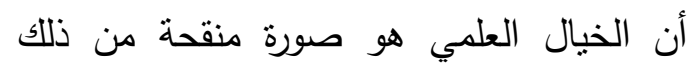

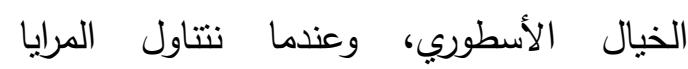

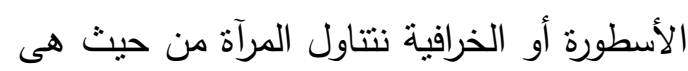
خرافة علمية (علم خرافي)، فعلم المرايا باختصار جامع بين الحقيقة والخيال، هو علم وخيال: علم الخيال وخيال العلم.

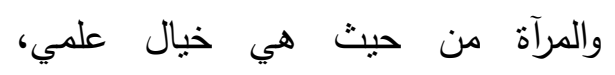
واعتبارها أداة سحرية ذات قدرات خارقة للعادة والطبيعة، إنما هي في هذا الجانب من جوانبها المتعددة امتداد منطور لما كان موجودًا في هي الماني

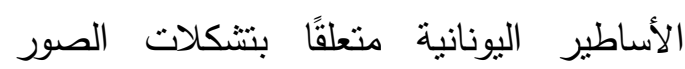
وتحولات الأثكال، أي صور وأثنكال الكائنات،

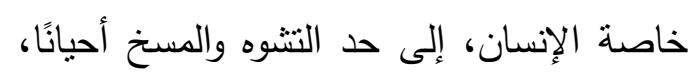

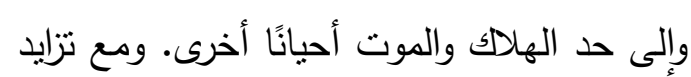
الاهتمام بالمرآة عند الإغريق والرومان، ظهر الريات ضرب من الممارسات السحرية، تلعب المرآة فيه دور الكثف عن المحجوب، إن نحن سألناها، 
أنها آخر "غيره"، ومجرد صورة "مختلفة" عنه

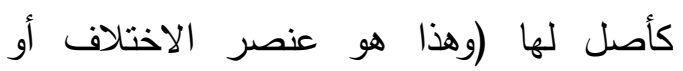
الغيربة).

من هذا الإحساس الحقيقى لهذا الفعل المزدوج للمرآة، بنطلق الخيال، ويُستخدم مجاز المرآة على أنحاء منباينة تصل إلى حد التضاد لئل التام، إذ تكون المرآة رمزاً للحقيقة عند البعض إنه لهن ورمزًا للبطلان والخداع عند البعض الآخر . والمرآة من حيث هي رمز للخداع، وكذلك من حيث هي رمز للمعرفة تتضمن تحولاً يطرأ على الإنسان الناظر إليها، ويتمثل هذا التحول في الوعي - ولو كان وعيًا ضئيلاً - بأن ثمة المّان معرفة بنفسه أو بغيرهن، وحتى الوعي بالخداع

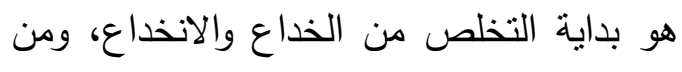
ثم يؤدي إلى معرفة النفس على حقبقتها. فالوعي هو نوع من المشاركة الفعالة والإيجابية مطلوب من الإنسان حامل المرآة، لكي تحقق لون المرآة هذا التحول فيه، أى نستطيع القول إن هن المرآة هى وسيلة تغيير وتصحيح، من أجل أن يرقى الإنسان، سواء فى معرفته أو فى سلوكه، إلى مرنبة أعلى مما هو عليه فى الواقع. ويذكر الكاتب أن علاقة الإنسان بالصورة، سواء صورته هو نفسه أو صورة آخر غيره، إنما

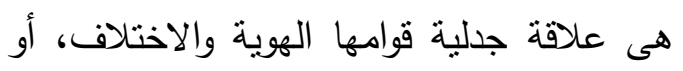
العينية والغيرية معًا. والوحدة التى تتحقق من خلال هذه العلاقة ليست وحدة مطلقة ساكنة،
الأعداء، ومرايا تليسكوبية، تتوجه إلى جميع الاتجاهات: إلى داخل البلاد وخارجها فتُرِى البعيد جدًا، ومرايا تكهنية تبين المستقبل وتكثف ما في الغيب وترصد الطقس والتربة، ومرايا دفاعية ضد الأخطار . مابر ويتحدث الفصل الثاني من الباب الأول من كتابنا - المعنون بـ "كرم المرآة" - عن أفعال المرآة وأغلاطها. وأول أفعال المرآة وأهمها، هو به أنها تعكس ما يقوم أمامها من أشخاص وأثنياء، بما فى هذا الفعل العرضي "تعكس" من ازدواج فى الدلالة أو ما ينطوى عليه من معنيين متضادين: فهى تعكس بمعنى النقل الأمين الصادق، أى تعطي صورة أمينة للأصل، ولكنها فى الوقت ذاته تعكس بمعنى النقل غير الأمين،

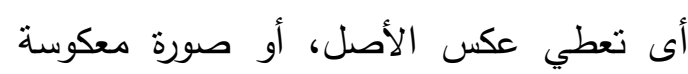
منه. ومن هنا، فعندما يرى الإنسان صورته في المرآة نسخة طبق الأصل منه (أى مطابقة له)، فهو يرى في الوقت ذاته يده اليمنى في الصورة يسرى واليسرى يمنى، وهو ما يُسمى علميًا بالانقلاب الجانبي.

هذا الفعل المزدوج للمرآة فعل حقيقي وواقعي، وهو أساس ذلك الإدراك الجدلي لدى الإنسان لما يقوم بينه وبين صورته المرآوية من "هوية واختلاف" او "عينية وغيرية". فهو وإن يدرك أن صورته "هي هو" أو "هي عينه" (وهذا هو عنصر الهوية أو العينية)، فإنه يدرك أيضًا 
ومن أجل استخلاص العِبرَ والفِكَر .

أما أغلاط المرآة، فإن ما تفعله المرآة من ظواهر خادعة أو أوهام وأباطيل جعل الكثيرون من الفلاسفة يعتبرونها رمزًا للزيف والخطأ. بل إن "الأغلاط" و "المغالطات" ألفاظ نجدها في لرئ مؤلفات علماء البصريات والمرآويات. والمغالطات الناشئة عن المرايا المختلفة، والتي أثنارت فلاسفة منل أفلاطون وأبوليوس، قدان صيغت صياغات رياضية مع براهين هندسية، وأخذت شكل النظريات عند إقليدس، وإيرون براتين السكندري، وابن الهيثم، وفتلو • فعلم المرآويات -

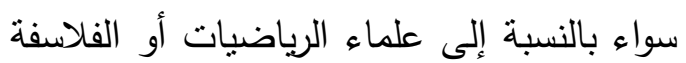

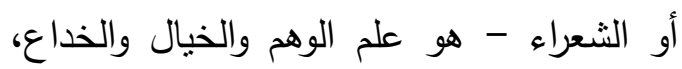
هذا من ناحية، ومن ناحية أخرى فإن الأوهام والأغلاط والمظاهر الخادعة التي تصنعها ناهن المرايا الكربة المقعرة والمحدبة، وكذلك المرايا المؤلفة من عناصر مستوية عديدة: طبيعية أو صناعية، أدت في كثير من الأحيان إلى نسج حكايات خرافية وإبداع أعمال فنية، خاصة في

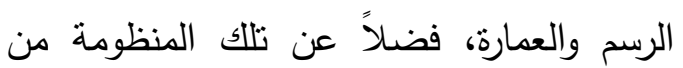
الرموز والمجازات والتصورات التي حفل بها

$$
\text { الأدب والتصوف والفلسفة. }
$$

ومن أغلاط المرآة الكرية المقعرة تكبير صورة الجسم، فيبدو الأصبع مثناً في حجم

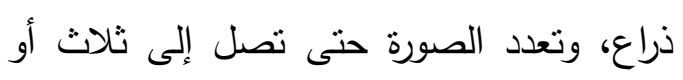
أربع صورإن كان موضع الجسد قريبًا من مركز
كتلالك التى نراها في النيرفانا الهندية، وعند بعض

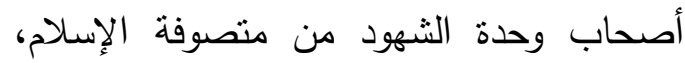
وإنما هي وحدة خلاقة دينامية، تقوم على الاختلاف أو الغيرية، كما تقوم على التبادل في العلاقة بين العارف والمعروف، فمثلما الإنسان عارف لله فهو معروف من الله. ومن أفعال المرآة الأخرى أنها "تثىى" صور الإنسان الثاخص أمامها، فيصبح في الاحري الهمان وقت واحد شاهدًا ومشهودًا، أو رائيًا ومرئيًا، بل هيخ إنها لتفعل أكثر من ذلك، فلو وقف بين مرآتين، "تعدّدت" صورته إلى ما لا نهاية.

ولا يحسن فهم التصورات الفلسفية الناشئة لأفعال المرآة إلا إذا نظرنا إليه من خلال إطار علاقة الفلسفة المتينة والقديمة بالمرآة عمومًا. فمنذ زمان طويل كانت الحكمة أو الفطنة يُرمز لئه إليها فى الفن ، تصويرًا ونحتًا على السوائين بإمرأة تمسك بيدها مرآة تتأمل فيها نفسها وتحت قدميها حية تسعى. وكل من المرآة والحية رمز للحكمة يرجع إلى "الكتاب المقد". ومتلما ترمز المرآة إلى الرؤية الثاقبة، ترمز أيضًا إلى الفكر السديد والعقل الناقد. والدليل على ذلك أن الفعل اللاتيني الدال على لـى انعكاس المرآة، أي ارتداد الضوء الساقط على دلى انى سطحها مرة ثانية، يعني في نفس الوقت "التأمل"

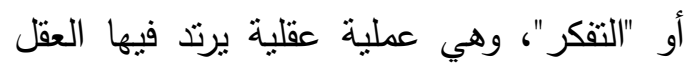
على نفسه من أجل إعادة النظر فيما بعقله، 
المسماة بأجهزة "الرؤية عن بعد" كالتليفزيون.

ومتلما يستخدم هذا العالم الوهمي الذى

هو من خلق العلم المعاصر لأغراض سلبية كالتضليل والخداع والتصوير، يستخدم لأغراض إيجابية منل "تجسيد الأفكار" بواسطة الصور لهور الكمبيوترية وتصور بدائل كان يتعذر التوصل إليها. ولكن بلا شك فإن المتفوقين تكنولوجيًا وحدهم الذين ينفردون بامتلاك أسرار استخدامه في الحالتين على السواء، إن سلبًا وإن إيجابيًا، مما بترتب على ذللك زيادة سبطرة أقلية على مقرات البشرية.

ولكن الأمر لا يقتصر على السياسة فقط، أي على عالم منقدم صانع للصور، قادر على الى اجنياز المرآة (رمزًا للقدرة التكنولوجية الخارقة) التي تتيح له النفاذ عبر المرآة ورؤية ما يقوم خلفها على الجانب الآخر، وعالم متخلف يتعامل مع الصور المنعكسة على سطح المرآة،

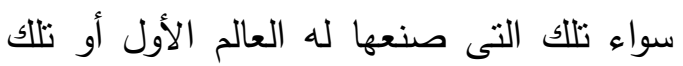

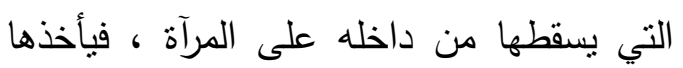

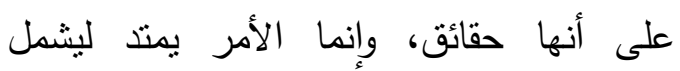

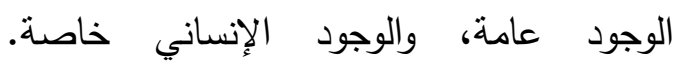
فالإنسان في العالم المتخلف، وفى العالم المتقام على السواء، إنما يوجد في عالم من الصور . ويذكر الدكتور محمود رجب أن الإنسان يرى الصورة بوصفها صورة، ويرى في الماء الواقعي ظاهرة واقعية تحنوي فى داخلها على بلى
المرآة. أما إذا بَعُد عنه فإن الصورة تتقلب أو تتعكس، فتظهر القدمان فى أعلاها والرأس في أسفلها. فضلاً عما تصنعه هذه المرآة من أثباح وأطياف تخرج من سطحها فنتبدى طائرة في هنه الهواء. ولكن على الرغم من صباغة هذه هري الظواهر البصرية والأغلاط صباغات رياضية

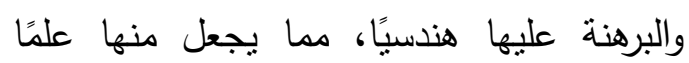
دقيقًا، فإن حكايات خرافية عديدة قد نشأت عنها.

وأما أغلاط المرآة المستوية فقد عرضنا لها أيضًا، خاصة انقلاب الصورة جانبيًا، فيكون الجانب الأيمن منها جانبًا أيسر وبالعكس، وتعدد الصورة إذا ما كان الجسم قائمًا بين مرآتين. غير أن هذا الفعل الخطأ الأخير يمكن أن أن أنسان يظهر بشكل أقوى وأوضح في مرآة مستوية واحدة مركبة من عدة مرايا مستوية، تمس حافة الواحدة منها حافة الأخرى داخل دائرة مقفلة أو مدابه

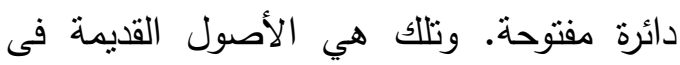
علم البصريات وعلم المرآويات لما نراه في الأفلام السينمائية من حيل تقوم على تعدد

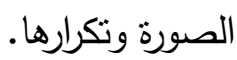

هذا العالم من الصور المتحركة والخيالات العابرة الذى تصنعه أغلاط المرايا وأفعالها، أصبحنا لا نراه في غرف العجائب ومعارض المرايا ومدن الملاهى، بل أصبحنا نحياه واقعًا

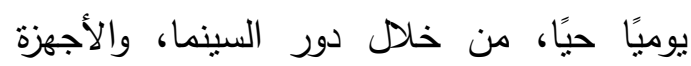


مثل حركات السحب وهي تمر في هذه السماء

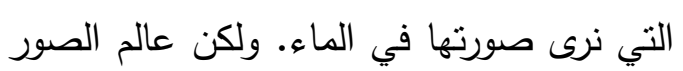

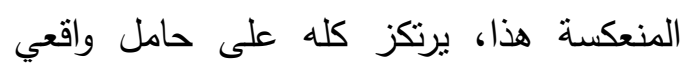

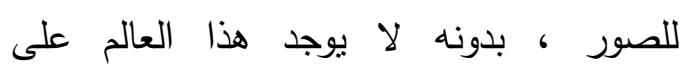
الإطلاق • وهذا يعني أن حامل الصور إنما لإنا

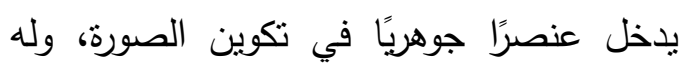

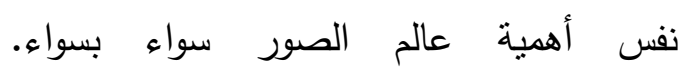

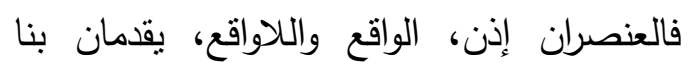

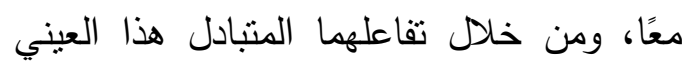

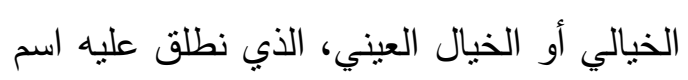
"الصورة المنعكسة".

وينكون الباب الثاني - بعنوان "تجربة

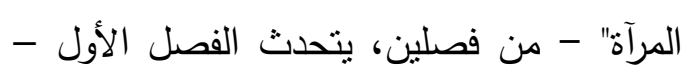
وهو بعنوان "أنا - آخر" - منه عن المرآة وما لآل

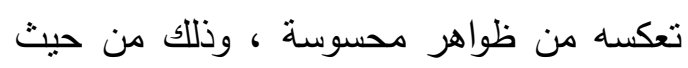

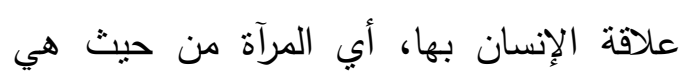

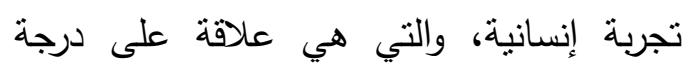
كبيرة من العمق والتعقيد معًا ؛ لأنها ترتكز على على دلى درجية

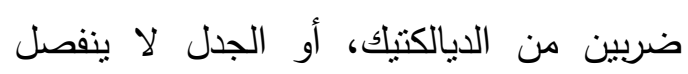
أحدهما عن الآخر.

وكل إنسان يعرف المرآة بحسب تجربنه

الخاصة وبحسب ملاحظاته اليومية لما يجري حوله في الحياة الإنسانية. وكذلك انعكاس المرآة من حيث هو ظاهرة معروفة لنا ومألوف لدينا،

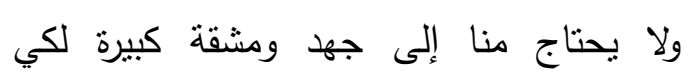
نكتثفه. المرآة وانعكاسها كلاهما إذن عنادي كئر
شىء لا واقعي، ففي الماء الواقعي يدرك

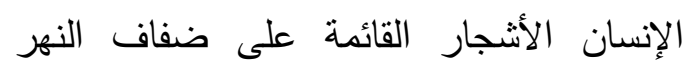
وسحب السماء، ولكنه وهو برى كل ذللك لا لا لإنهان

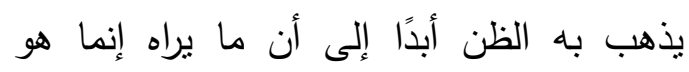

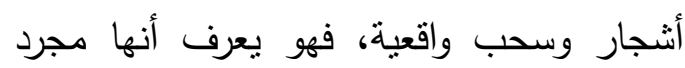
صور ، لها أساس طابع المظهر، أي اللاواقع. إن رؤية الإنسان لعالم الصور المنعكسة

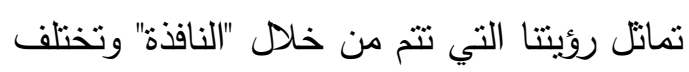

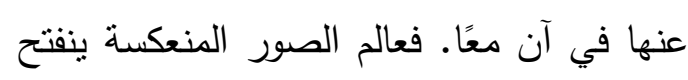

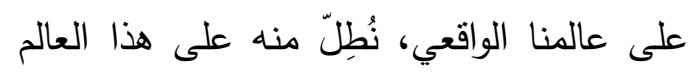

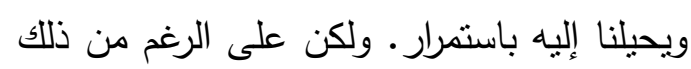

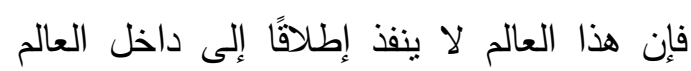

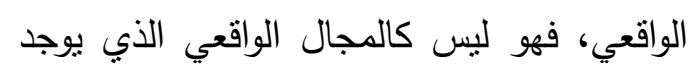

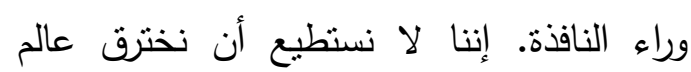
الصور المنعكسة، ولا نستطيع أن نطأه بأقدامنا،

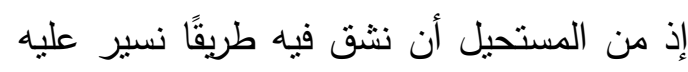

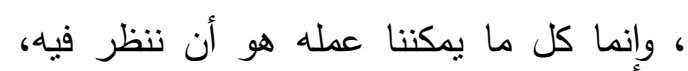

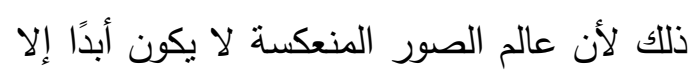
فى هذه النظرة ، ولا يمكن أن يكون إلا أثنبه

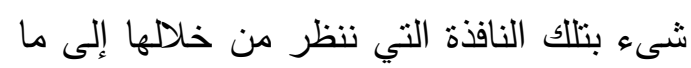
فيه من أنثياء منعكسة. ولعالم الصور المنعكسة مكان خاص به يختلف عن الدكان الخاص بنا الذى نألفه

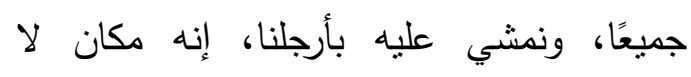

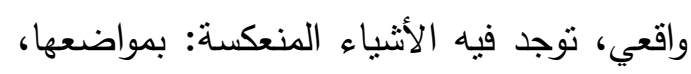
وعلاقاتها بعضها بعض، بل بل وحركاتها اللاواقعية 
كانت - من وجهة نظره هو الشخصية أو الذاتية - لا تتقل الحقيقة، أي الحقيقة الباطنية، هونة أي حقيقة ذاته كما يشعرها على نحو داخلي بينه وبين نفسه. غير أن المرآة تستخدم في لئي حالات أخرى استخدامًا رمزيًا، لتقوم بدور لتهري معاكس تمامًا: إذ تتقل هذه الحقيقة الباطنة التي لا يدركها إلا الشخص وحده، والتي يريد

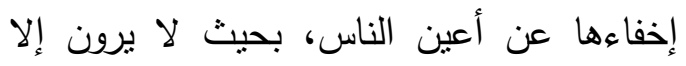
المظهر الذي يتبدى به فقط. استخدم بعض الأدباء تكنيك المرآة، والذى يقوم في جوهره على عملية الإسقاط، فالثخصية من تلك الثخصيات المرضية نراها تقوم بإسقاط كل أو بعض ما بدور في داخلها من مشاعر

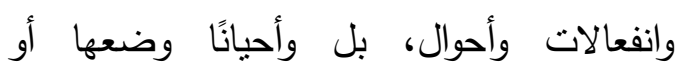

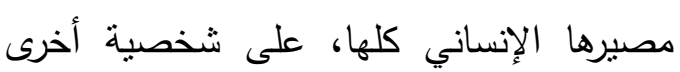
تكون لها كالمرآة أو الظل.

أما مسألة القرين من زواية وجودية

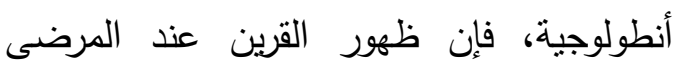
النفسيين يعدّ علامة على إخفاقهم إخفاقًا كاملاً في الاتصال مع الواقع والتعامل معه، بل وعلى إحلى إحلى إخفاقهم الثامل في التواصل مع ذواتهم والتآلف معها. فالإنسان السوي لا يخاف من خياله أو ظله، ويعرف كيف يتحرر من الأوهام والأشباح.

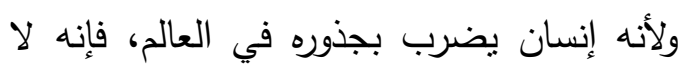

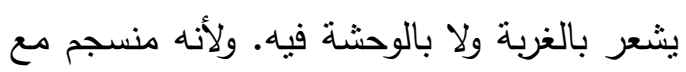
العالم ومع نفسه، فإنه يحقق وجوده، ويؤكد
معتاد بالنسبة إلى الإنسان، وخاصة ذلك الذي يعيش في عالم الحضارة والمدنية ؛ حيث يكون للصغار وللكبار على السواء تجربة بالمرآة، يحصلونها من خلال ألوان شتى من النشاط.

ومن الأمور التي لا سبيل إلى إنكارها أن تجربة المرآة بمعناها الدقيق، تتحقق عند الطفل بدرجة أكثر وضوحًا وتعقيدًا عن الإنسان

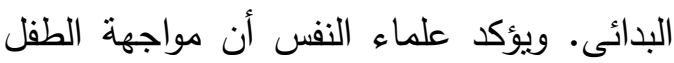
لصورته في المرآة إنما هي عامل هام من عوامل إدراكه الثعوري لوجوده الثخصي من حيث هو كلية حية متمايزة عن الوسط الذي يعيش فيه، أي من حيث هو هوية شخصية مستقلة.

تتعرض علاقة الإنسان بصورته لألوان شتى من الخلل والاضطراب، فيفقد بذلك وعيه الديالكتيكي، فلا يتمكن من إدراك ذاتيته وهويته

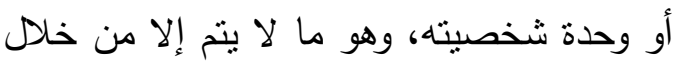
إحساسه بالاختلاف والتمايز عن الآخر أو الأنا أو الأنا الآخر المنعكس أمامه في المرآة. وتكون النتيجة تجاوز عتبة السواء والصحة، والدخول في دائرة المرض النفسي والعقلي التي تتفاوت درجته قوةً أو ضعفًا.

كانت المرآة تمثل وجهة نظر الناس الآخرين، أو لنقل : وجهة نظر الموضوعية -

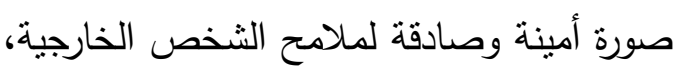
إنها تقدم، باختصار، مظهره الخارجي، وإن 
يمكن فصلها عن الطبيعة وعن نأثير الآخرين. فالذات فى المرآة ليست سوى جزء من الذات

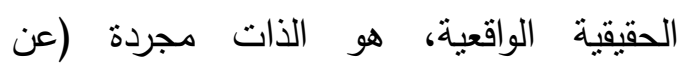
الطبيعة). لكن هذا لا يعني أنها ذات مثالية أو هئه

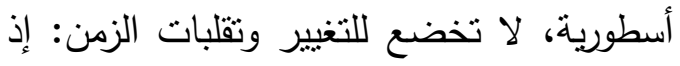
كلما كانت المرآة مجلوة، وكلما كان الضوء الساقط علبها كافيًا، كانت أقدر على إظهار ماه يطرأ على الذات من آثار السن والمرض وخيبة الأمل والإحباط والضعف .. إلى آلى آخر هذه الآثار التى تتخارج هنالك فى المرآة مثلها منل الصحة والفرح والأمل والثقة. ولا شك أن الن لهاه الإنسان حينما يكون منسجمًا مع العالم ومتحدًا به، فإنه لا يحتاج إلى المرآة، ذلك أن حاجته إليها إنما تشتد فى فترات التفكك النفسي؛ حيث إنى يبدأ في الالتفات إلى ثللك الصورة المتوحدة ليرى ما الذى طرأ عليها بالفعل، وما الذي تعكسه مما ليأل يجري في داخله، وما الذي ينوي عمله بعد ذللك كله. فالمرآة إذن تعكس إلى الخارج ذلك العالم الداخلي للإنسان : عالم الذات.

وتحليل موضوع المعرفة (التشريح) وتأمله (المرآة) تعبيران عن نشأة عمليتين مترابطنين من العمليات العلمية الحديثة من ناحية، وطريقتان أو وسيلتان منكاملتان من أجل الوصول إلى الحقيقة من ناحية أخرى.

ولو تحدثا عن "الخيلاء" وهي تديم النظر فى المرآة، وهي علامة رمزية على اهنمامها
شخصيته على نحو واقعي. أما الاتصال السيء بالواقع، وفقدان الإحساس بالواقع فيعبران عند الإنسان غير السوي عن خلل واضطراب في أعماقه. ولأنه إنسان منتزع الجذور من العالم،

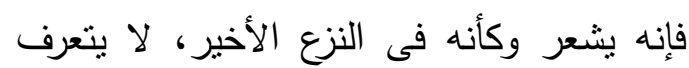
على نفسه فى البيئة المحيطة به ولا في أفعاله التي تصدر عنه. ومن هنا يظهر القرين عرضًا من أعراض الاغتراب ، وغربة الذات.

إن الإنسان الذي يعاني من اضطرابات نفسية أو عقلية حادة، أو الإنسان المجنون بوجه الإنسان

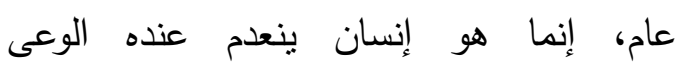
الديالكتيكي الذي يقوم على إدراك الهوبة في لئي الاختلاف، وغالبًا ما يكون أسبرًا لذلك الوعي الترم المزيف المغترب الذي بتميز بالنظر إلى الآخر،

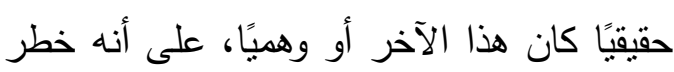

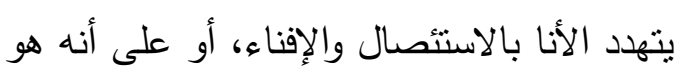

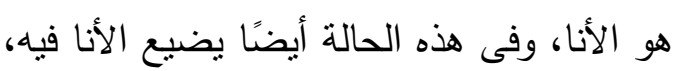
لأن هنالك توحدا نرجسيًا به حتى الموت. أما الفصل الثانى - بعنوان "الراوي - فان

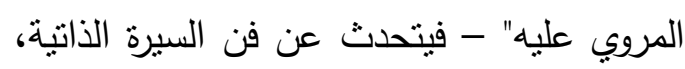
فيذكر الكاتب أن استخدام المرآة الزجاجية فى فئه القرنين السادس عشر والسابع عشر علامة بارزة

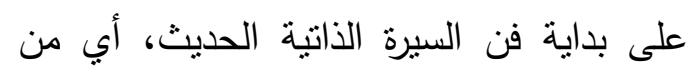
حيث هى صورة للذات: بأعماقها، وأسرارها، وأبعادها الداخلية؛ حيث تسنطيع المرآة أن تحيل

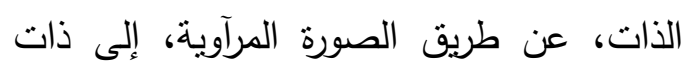


خارجية أو خبرة داخلية، أو كان اتحاد هاتين

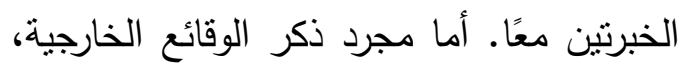

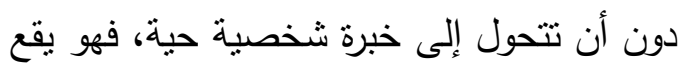
فى باب الدذكرات أكثر منه فى باب السيرة الذانية. والسيرة الذانية تتميز أساسًا بأنها تعكس باب السيرة التفاعل المتبادل بين العالم وبين الفرد في مسار

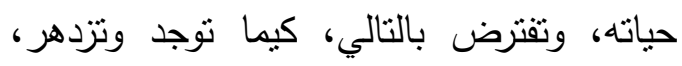
وجود شخصية فردية فعالة وعالم زاخر بالحيوية والنشاط.

وكل سيرة ذاتية هي تاريخ نتكيل شخصية وتكوينها، أو رواية بناء الثخصية،

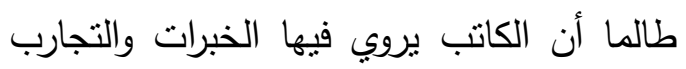

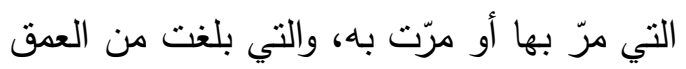
درجة عملت معها على تربيته ونعليمه، وكيف استطاع من خلالها تتكيل نفسه وبناء ذاته.

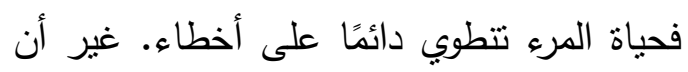

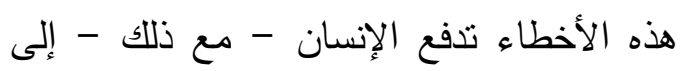
الأمام، إذ الخبرة معناها التعلم من أخطاء

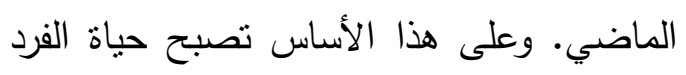
خصبة ثرية : فالنجاح ، حتى ولو كان طارئًا

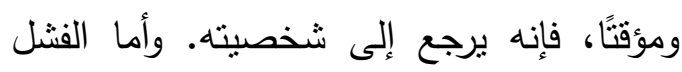
فهو نسبي، لأنه قد يستخلص منه درسًا أو عبرة

يستقيد منها.

وأخيرًا، فنحن أمام عمل مهم، فحتوى

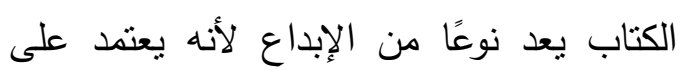

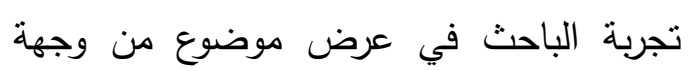

الجارف بمظهرها الخارجي الخادع، أما المرآة ذاتها فهي لا تخدع. إنما هي وظيفة رمزية، نُسبت إليها كغيرها من وظائف، فعند المعجبين

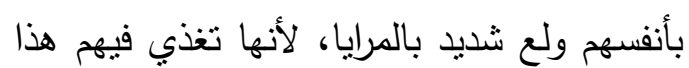

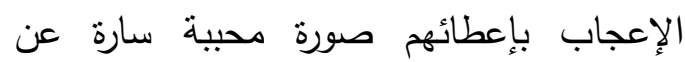
ذواتهم الخارجية. ومن هنا كانت وظيفة المرآة فى الرياء والنفاق، وكان الربط بين المرآة والمنافق. فالمنافق إذن مخادع.

كان هناك اهتمام كبير، في عصر النهضة، بالسوداء أو الكآبة (المالنخوليا)، وهي النيان ترتبط في ذلك الزمان بأحاسيس منباينة من الفقد والضياع والوحدة في العالم. واتخاذ الذات الكاتبة

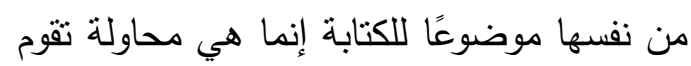
على ذلك التأمل المرآوي الوهمي الذي تهدف

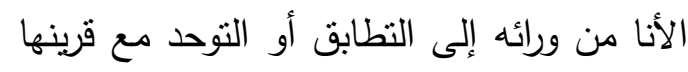

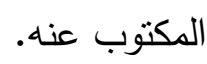

تدور السيرة الذاتية دائمًا حول نقطة

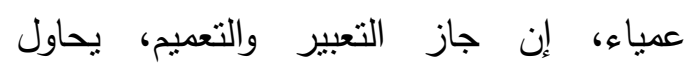

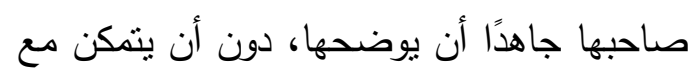
ذلك أن يراها بوضوح كامل، ومن هنا ينشأ الصراع عنده بين رغبة عارمة في المعرفة واستحالة الوصول إلى هذه المعرفة الكاملة، وهو الصراع الذي يحاول التظلب عليه بالكتابة.

وهناك عدة خصائص تميز السيرة الذانية.

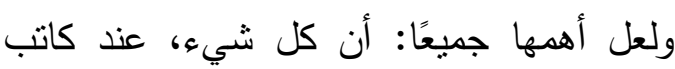
السيرة الذاتية، إنما هو خبرة ، سواء أكانت خبرة 
نظره، وهو عمل فريد أيضًا، لأننا لم نقرأ كتابًا آخرًا في نفس الموضوع. هذا العمل الواحد الموجود بالعربية في موضوعه. والأكثر من ذلك أنه كتاب ممتع جدًا. وكثثرًا ما تأني فكرة ما في موني ذهننا، ثم تتظر لتجدها أمامك في حضور جميل، ونجد كثرة المعلومات الفلسفية والأدبية والاستعانة بالروايات العالمية أيضًا. ويهم هذا العمل الضخم المهتمين بعلم

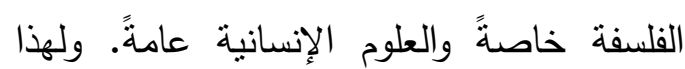
فالكتاب لا غنى عنه في المكتبات العامة والمكتبات الأكاديمية الإنسانية. 